\title{
A case of Kallmann syndrome associated with a non-functional pituitary microadenoma
}

\author{
Taieb Ach1, Hela Marmouch1, Dorra Elguiche1, Asma Achour2, Hajer Marzouk1, \\ Hanene Sayadi1, Ines Khochtali1 and Mondher Golli² \\ 'Departments of Internal Medicine and Endocrinology and 2Radiology, University Hospital Fattouma \\ Bourguiba Monastir, Monastir, Tunisia
}

\author{
Correspondence \\ should be addressed \\ to M T Ach \\ Email \\ ach.taieb@gmail.com
}

\section{Summary}

Kallmann syndrome (KS) is a form of hypogonadotropic hypogonadism in combination with a defect in sense of smell, due to abnormal migration of gonadotropin-releasing hormone-producing neurons. We report a case of a 17-year-old Tunisian male who presented with eunuchoid body proportions, absence of facial, axillary and pubic hair, micropenis and surgically corrected cryptorchidism. Associated findings included anosmia. Karyotype was 46XY and hormonal measurement hypogonadotropic hypogonadism. MRI of the brain showed bilateral agenesis of the olfactory bulbs and $3.5 \mathrm{~mm}$ pituitary microadenoma. Hormonal assays showed no evidence of pituitary hypersecretion.

\section{Learning points:}

- The main clinical characteristics of KS include hypogonadotropic hypogonadism and anosmia or hyposmia.

- MRI, as a non-irradiating technique, should be the first radiological step for investigating the pituitary gland as well as abnormalities of the ethmoid, olfactory bulbs and tracts in KS.

- KS may include anterior pituitary hypoplasia or an empty sella syndrome. The originality of our case is that a microadenoma also may be encountered in KS. Hormonal assessment indicated the microadenoma was nonfunctioning. This emphasizes the importance of visualizing the pituitary region in KS patients to assess for hypoplastic pituitary malformations or adenomas.

\section{Background}

Kallmann syndrome (KS) is a rare disorder first described in 1856 and later studied by Kallmann in 1944 (1). It is now designated as olfactogenital dysplasia with an association between agenesis of the olfactory bulbs and hypogonadism. The prevalence of KS is still unknown. The reported incidence is 1 in 8000 to 1 in 10000 in men and is rarer in women (2). KS is a genetically heterogeneous disease. Its inheritance may be X-linked, autosomal dominant or autosomal recessive. There are more than 24 genes underlying KS that have been identified (3). Mutations in these genes are thought to interfere with expression of cell markers that guide migrating neurons, leading to failed migration of $\mathrm{GnRH}$ neurons and olfactory neurons to the forebrain during fetal development. The main clinical characteristics of KS include hypogonadotropic hypogonadism and anosmia or hyposmia. Less common phenotypes include cardiovascular anomalies, unilateral renal agenesis, cleft palate and cleft lip, cryptorchidism and osteoporosis (4). Magnetic resonance imaging (MRI) can show abnormalities of the olfactory system and other forebrain structures (5). Other abnormalities may be discovered by using MRI because of its high resolution and multiplanar capabilities, such as pituitary abnormalities (6). The association of KS with a pituitary microadenoma has not been well described in the literature. 
In this case report study, we describe a combination of KS discovered in the setting of a delayed puberty and olfactory impairment, and an MRI finding of a pituitary microadenoma.

\section{Case presentation}

A 17-year-old Tunisian male presented at the department of endocrinology and internal medicine of the University Hospital Fattouma Bourguiba Monastir, for absent pubertal development. He was born to consanguineous parents and had normal delivery. He has no siblings. He was circumcised, but micropenis was not noted at birth. He had normal developmental milestones. Family history was notable for anosmia in the mother, maternal aunt and grandmother. Bilateral cryptorchidism was discovered at age six years and surgically corrected. The patient had intellectual disability causing him to stop his studies at the age of 14 years after failing to advance in school.

Physical examination showed a young man profile with a eunuchoid body proportion (Fig. 1). He had a body weight of $74 \mathrm{~kg}$, height of $169 \mathrm{~cm}$, arm span was $174 \mathrm{~cm}$ and body mass index of $26 \mathrm{~kg} / \mathrm{m}^{2}$. He had a bilateral gynecomastia without galactorrhea. His secondary sexual characters were deficient (Tanner stage 1). He had micropenis (stretched phallus length $2.5 \mathrm{~cm}$ ). The scrotal contents were barely palpated on both sides. Scrotal ultrasound revealed prepubertal testes $(0.1$ and $0.2 \mathrm{cc})$. Neurologic examination was otherwise unremarkable except for decreased sense of smell.

Hormonal assays identified a hypogonadotropic hypogonadism profile with total testosterone $0.05 \mathrm{ng} / \mathrm{mL}$ (normal range $>2.5 \mathrm{ng} / \mathrm{mL}$ ), luteinizing hormone (LH) $0.1 \mathrm{IU} /$ $\mathrm{mL}$ (normal range 2-11) and follicle-stimulating hormone (FSH) $4.5 \mathrm{IU} / \mathrm{mL}$ (normal range 1-11). The prolactin was normal with a serum level of $250 \mathrm{IU} / \mathrm{mL}$ (normal <400IU/ $\mathrm{mL}$ ). Testing with human chorionic gonadotropin (HCG) $5000 \mathrm{IU}$ was performed to test Leydig cell testosterone secretion. Optimal response on the fifth day showed a small increase in testosterone serum level of $0.1 \mathrm{ng} / \mathrm{mL}$.

Abdominal ultrasonography revealed normal liver, spleen, kidneys and bladder. Karyotyping showed 46XY pattern. Karyotype pattern is important thus to rulingout Klinefelter syndrome, which is a common cause of hypogonadism in males. MRI of the brain showed bilateral agenesis of the olfactory bulbs (Fig. 2). MRI also revealed a $3.5 \mathrm{~mm}$ pituitary microadenoma (Fig. 3). Clinical biochemical and radiologic findings were consistent with KS.

The patient was started on androgen replacement injections to induce virilization. He received

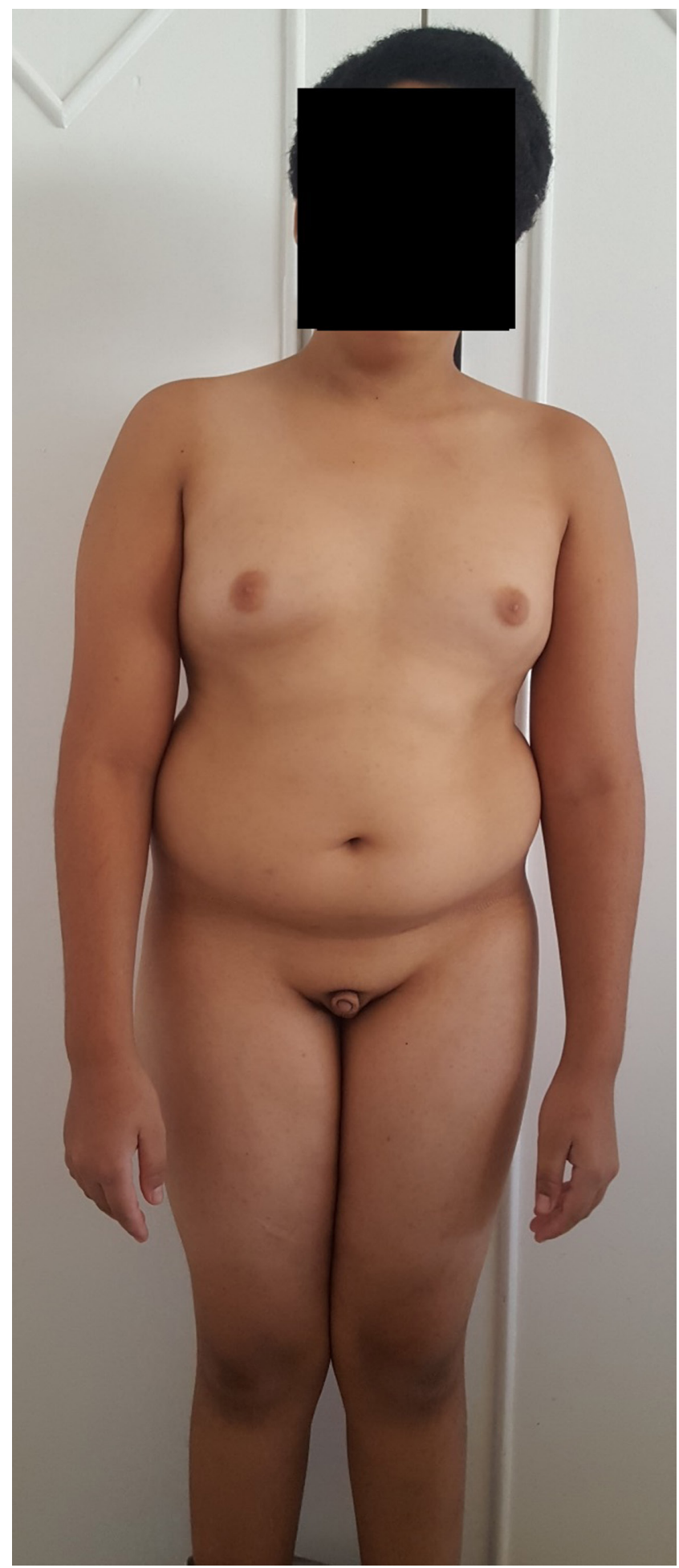

Figure 1

Eunuchoid body proportion with bilateral gynecomastia.

intramuscular testosterone injections $(50 \mathrm{mg}$ every 3 weeks) with a gradual dose increase to $250 \mathrm{mg}$ per month. The evaluation after 3 months of regular 


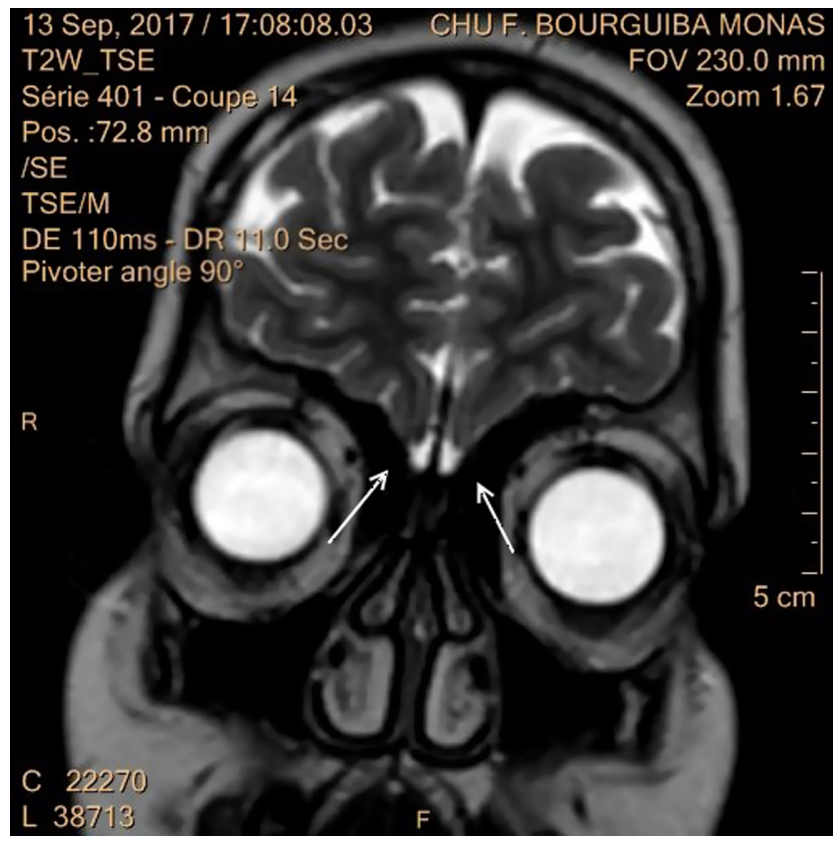

Figure 2

Coronal-weighted MRI image showing bilateral olfactory bulb agenesis.

follow-up showed a change in voice becoming deeper and appearance of coarse pubic hair. Morning erections were reported, the testes and penis increased in size respectively (testes $=2 \mathrm{cc}$, phallus $=4 \mathrm{~cm}$ ). Serum testosterone increased to $1.5 \mathrm{ng} / \mathrm{mL}$.

\section{Discussion}

We report a case of a rare association of KS with a nonfunctional pituitary microadenoma. KS is an isolated form

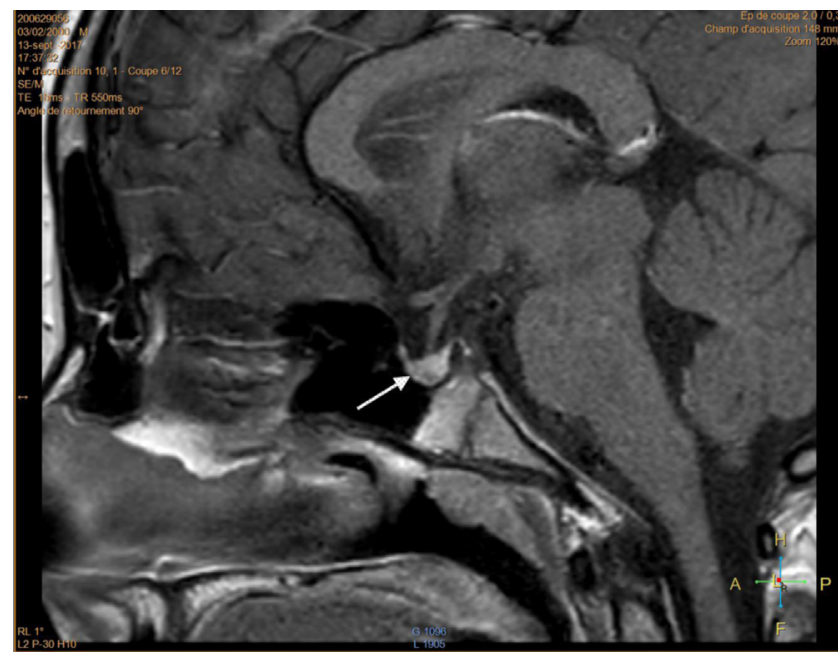

Figure 3

Sagittal-weighted MRI image demonstrating a microadenoma of $3.5 \mathrm{~mm}$. of hypogonadotropic hypogonadism in combination with a defect in sense of smell. It is due to defects in olfactory structures (bulbs, grooves, tracts) and altered migration of GnRH-secreting neurons into the preoptic and hypothalamic regions (7).

The patient's clinical presentation seems to be concordant in the literature, with the classical association of hypogonadotropic hypogonadism and anosmia. KS may be diagnosed neonatally in cases of cryptorchidism and micropenis; yet, patients are primarily diagnosed later due to absent pubertal development (4), with a lack of secondary sexual characteristics, as was the situation in the present case.

It is a heterogeneous genetic disorder that may be transmitted in an X-linked, which is the most prevalent, autosomal recessive or dominant pattern as well as cases of oligogenicity (8). While no genetic investigations were undertaken in family members, the anosmia in the maternal family history is consistent with variable expressivity and incomplete penetrance observed in KS (8).

Clinical manifestations of KS occur at variable rates (7) and may include cryptorchidism, micropenis and gynecomastia - as in our patient. Clinical examination of the scrotum in our case showed small testes consistent with the gonadotropin deficiency of KS. The evaluation of testicular secretions may be useful before hormonal replacement initiation, in order to check for remnant testicular tissues in the abdomen or to assess Leydig cell response to human chorionic gonadotropin (9).

MRI is highly valuable in evaluating suspected KS. Data suggest that, in hypogonadotropic hypogonadism, MRI being a non-irradiating technique, should be the first radiological step for investigating the pituitary gland as well as abnormalities of the ethmoid, olfactory bulb and tracts (10). In patients with suggestive clinical findings, MRI can contribute to the diagnosis of KS by visualizing defects in olfactory bulbs, sulci and tracts (4). To diagnose $\mathrm{KS}$, infiltrative disorders and space occupying lesions of the pituitary must be excluded. Recent studies have shown ethmoid bone abnormalities and pituitary anomalies on computed tomography in KS patients. The current study raises the possibility of detecting such findings using MRI $(9,10)$.

The central finding in the present case is the MRI finding of a non-functioning pituitary microadenoma in association with KS. This association has been previously reported by Bolu et al. (6) in their MRI assessment of 120 male patients with idiopathic hypogonadotropic hypogonadism. Patients with hypogonadotropic 
hypogonadism were diagnosed with microadenomas and irregularly contrasting pituitary in $18.2 \%$ and $10.7 \%$ of cases respectively (6). The previous study showed that MRI is useful in defining the morphological aspects of the hypothalamopituitary region in idiopathic hypogonadotropic hypogonadism. It is unclear if identified anomalies are as a result of the disease or a coincidence. Rare associations with arachnoid cyst have been reported in young adults (age range: 18-33 years) where the arachnoid cyst was asymptomatic and was incidentally detected during the diagnostic workup for hypogonadotropic hypogonadism. Recently, Bonomi et al. (11) reported the association between idiopathic hypogonadotropic hypogonadism and pituitary nonsecreting microadenoma in a nationwide cohort to be from $5 \%$ to $14 \%$.

In the study of Zhang et al. (5), evaluation of 14 patients with KS found hypoplastic anterior pituitary in 6 patients, but no pituitary adenomas. As reported in the literature, KS often includes anterior pituitary hypoplasia (height $<4 \mathrm{~mm}$ ), and the number of such reports has increased as showed by Dallago et al. (12) in two cases of KS with an empty sella syndrome. Rare associations have been reported, such as atypical presentation of a patient with both KS and a craniopharyngioma (13). However, craniopharyngioma seems more likely to be coincidental, rather than linked with developmental anomalies typically observed as part of the clinical picture of KS. In our case, MRI assessment showed a $3.5 \mathrm{~mm}$ microadenoma, and hormonal analysis did not reveal any additional abnormal hormonal secretion. The patient had no complains of any compressive symptoms (i.e. visual field disturbance). Prior MRI studies of idiopathic hypogonadotropic hypogonadism showed that microadenomas were more frequently compared to healthy controls. Gonadotropin function is particularly sensitive to pituitary deficiency (6). Because of the rarity of both KS and pituitary adenomas, it is difficult to establish a relationship between these two conditions and associations should be considered as atypical as far as embryogenesis and pathophysiology are concerned.

Our main treatment objective was to induce the development of secondary sexual features and erectile function. Testosterone is the standard treatment when fertility is not desired (1), and it effectively induced secondary sexual characteristics in our patient.

\section{Conclusion}

KS is a developmental disorder characterized by the association of isolated hypogonadotropic hypogonadism and anosmia/hyposmia. Olfactory MRI imaging may aid in the diagnosis of KS in patients with suggestive clinical findings. Pituitary adenoma is a rare association with the KS. In our case, it was a non-functional microadenoma. This emphasizes the need to image the pituitary region in KS patients to assess for hypoplastic pituitary malformations or adenomas incidentaloma - as was the case in this patient. Early diagnosis of KS is important to ensure better quality of life.

\section{Declaration of interest}

The authors declare that there is no conflict of interest that could be perceived as prejudicing the impartiality of the research reported.

\section{Funding}

This research did not receive any specific grant from any public funding agency, commercial or not-for-profit sector.

\section{Patient consent}

Written consent has been obtained from the patient for publication of this article and the use of the patient's photograph.

\section{Author contribution statement}

Taieb Ach, Hela Marmouch and Dorra Elguiche were involved in data collection, patient care and follow-up. Hajer Marzouk, Hanene Sayadi and Ines Khochtali were involved in patient assessment, diagnosis and treatment. Taieb Ach was the main contributor in writing the manuscript. Asma Achour and Mondher Golli helped in the MRI interpretation and diagnosis of the microadenoma and olfactory abnormalities. All authors read and approved the final manuscript.

\section{References}

1 Arkoncel ML, Arkoncel FR \& Lantion-Ang FL. A case of Kallmann syndrome. BMJ Case Reports 2011 .25 30-39 (https://doi.org/10.1136/ bcr.01.2011.3727)

2 Dzemaili S, Tiemensma J, Quinton R, Pitteloud N, Morin D \& Dwyer AA. Beyond hormone replacement: quality of life in women with congenital hypogonadotropic hypogonadism. Endocrine Connections 20176 404-412. (https://doi.org/10.1530/EC-17-0095)

3 Vezzoli V, Duminuco P, Bassi I, Guizzardi F, Persani L \& Bonomi M. The complex genetic basis of congenital hypogonadotropic hypogonadism. Minerva Endocrinologica 201641 223-239.

4 Boehm U, Bouloux PM, Dattani MT, de Roux N, Dode C, Dunkel L, Dwyer AA, Giacobini P, Hardelin JP, Juul A, et al. Expert consensus document: European Consensus Statement on congenital hypogonadotropic hypogonadism - pathogenesis, diagnosis and treatment. Nature Reviews Endocrinology 201511 547-564. (https:// doi.org/10.1038/nrendo.2015.112)

5 Zhang Z, Sun X, Wang C, Wang G \& Zhao B. Magnetic resonance imaging findings in Kallmann syndrome: 14 cases and review of the literature. Journal of Computer Assisted Tomography 201640 39-42. (https://doi.org/10.1097/RCT.0000000000000334) 
6 Bolu SE, Tasar M, Uckaya G, Gonul E, Deniz F \& Ozdemir IC. Increased abnormal pituitary findings on magnetic resonance in patients with male idiopathic hypogonadotrophic hypogonadism. Journal of Endocrinological Investigation 200427 1029-1033. (https:// doi.org/10.1007/BF03345305)

7 Salama N. Kallmann syndrome and deafness: an uncommon combination: a case report and a literature review. International Journal of Reproductive Biomedicine 201614 541-544. (https://doi. org/10.29252/ijrm.14.8.541)

8 Maione L, Dwyer AA, Francou B, Guiochon-Mantel A, Binart N, Bouligand J \& Young J. GENETICS IN ENDOCRINOLOGY: genetic counseling for congenital hypogonadotropic hypogonadism and Kallmann syndrome: new challenges in the era of oligogenism and next-generation sequencing. European Journal of Endocrinology 2018 178 R55-R80. (https://doi.org/10.1530/EJE-17-0749)

9 Dash PK \& Raj DH. Biochemical and MRI findings of Kallmann's syndrome. BMJ Case Reports 2014 (https://doi.org/10.1136/bcr-2014207386)
10 Hacquart T, Ltaief-Boudrigua A, Jeannerod C, Hannoun S, Raverot G, Pugeat M, Brac de la Perriere A, Lapras V, Nugues F, Dode C, et al. Reconsidering olfactory bulb magnetic resonance patterns in Kallmann syndrome. Annales D'Endocrinologie $2017 \mathbf{7 8} 455-461$. (https://doi.org/10.1016/j.ando.2016.12.003)

11 Bonomi M, Vezzoli V, Krausz C, Guizzardi F, Vezzani S, Simoni M, Bassi I, Duminuco P, Di Iorgi N, Giavoli C, et al. Characteristics of a nationwide cohort of patients presenting with isolated hypogonadotropic hypogonadism (IHH). European Journal of Endocrinology 2018178 23-32. (https://doi.org/10.1530/EJE-17-0065)

12 Dallago CM, Abech DD, Pereira-Lima JF, Leaes CG, Batista RL, Trarbach EB \& Oliveira Mda C. Two cases of Kallmann syndrome associated with empty sella. Pituitary 200811 109-112. (https://doi. org/10.1007/s11102-007-0043-9)

13 Jonklaas J. Atypical presentation of a patient with both kallmann syndrome and a craniopharyngioma: case report and literature review. Endocrine Practice 200511 30-36. (https://doi.org/10.4158/ EP.11.1.30)

Received in final form 21 March 2018

Accepted 28 March 2018 